\title{
Numerical Application of Adomian Decomposition Method to One Dimensional Wave Equations
}

\author{
E. U. Agom ${ }^{1}$, F. O. Ogunfiditimi ${ }^{2}$ \\ ${ }^{1}$ Department of Mathematics, University of Calabar, Calabar, Nigeria \\ ${ }^{2}$ Department of Mathematics, University of Abuja, Abuja, Nigeria
}

\begin{abstract}
Adomian decomposition method (ADM) allows us to obtain the exact solution as an infinite series of functions to several classes of equations. It avoids discretization in space and time induced by classical methods of resolution of functional equations. In this paper, we state the general Adomian decomposition method for the wave equation and apply it to problems of one-dimensional wave equations. Four test problems were used to validate the reliability of the method. In all cases, the method gave exact solution in Taylor's series forms, which were the same as the compact analytical exact solution.
\end{abstract}

Keywords: Adomian Decomposition Method, One-Dimensional Wave Equations

\section{Introduction}

The Wave equations are nontrivial partial differential equations that seems to be everywhere in several places at the same time. The wave propagation represents one of the most common physical phenomena one experiences in everyday life [14]. They occur most frequently, through sight and hearing, but also through telecommunication, radar, medical imaging etc. Application in Industries ranges from aero acoustics to music acoustic (acoustic waves), from oil prospect to nondestructive testing (elastic wave) [13]. They also, occur from optics to stealth technology (electromagnetic wave) and stabilization of ships and offshore plate-forms.

In this paper, we limit ourselves to a one-dimensional space domain. This is a simple prototype example of all other kind of wave propagation models. There are a wide variety of numerical scheme for approximately solving the 1D wave (the acoustic wave). The uniqueness of the solution of a wave equation is obtained by imposing additional conditions. Typically, the value of the function and some of its derivative at initial conditions called the Cauchy data. Such equations are referred to as Cauchy problems.

Recently, Adomian decomposition method (ADM) [5] has been an effective mathematical tool for obtaining approximate and analytical solutions to some of the nonyielding ordinary and partial differential equations [1], [2], [3], [4], [6], [7] and [12]. And the results are closed to being called exact, in fact exact in many situations.

\section{The Concept Adomian Decomposition Method for 1D Wave Equation}

The general wave equation is given as

$$
\mathrm{u}_{\mathrm{tt}}=\mathrm{c}^{2} \Delta \mathrm{u}, \mathrm{x} \in \mathfrak{R}^{\mathrm{m}}, \mathrm{t} \triangleright 0
$$

when $\mathrm{m}=1$, the Cauchy data are given as

$\mathrm{u}(\mathrm{x}, 0)=\mathrm{g}(\mathrm{x}), \quad \mathrm{u}_{\mathrm{t}}(\mathrm{x}, 0)=\mathrm{h}(\mathrm{x})$

where $\mathrm{c}^{2}$ is a physical constant denoting the ratio of tension to mass per unit length. By $\mathrm{ADM}$, for $\mathrm{m}=1$, we write

\section{equation (1) as}

$\mathrm{L}_{\mathrm{t}} \mathrm{u}=\mathrm{c}^{2} \mathrm{u}_{\mathrm{xx}}$

where

$\mathrm{L}_{\mathrm{t}}=\frac{\partial^{2}}{\partial \mathrm{t}^{2}}$

The inverse $\mathrm{L}_{t}^{-1}$ is a two-fold integral operator, hence we obtain

$$
\begin{gathered}
\mathrm{L}_{\mathrm{t}}^{-1} \mathrm{~L}_{\mathrm{t}} \mathrm{u}=\mathrm{g}(\mathrm{x})+\mathrm{th}(\mathrm{x})+\mathrm{L}_{\mathrm{t}}^{-1} \mathrm{c}^{2} \mathrm{u}_{\mathrm{xx}} \\
\mathrm{L}_{\mathrm{t}}^{-1} \mathrm{~L}_{\mathrm{t}} \mathrm{u}(\mathrm{x}, \mathrm{t})=\mathrm{u}(\mathrm{x}, \mathrm{t})=\sum_{\mathrm{k}=0}^{\infty} \mathrm{u}_{\mathrm{k}}(\mathrm{x}, \mathrm{t}) \\
\mathrm{g}(\mathrm{x})+\operatorname{th}(\mathrm{x})=\mathrm{u}_{0}(\mathrm{x}, \mathrm{t}) \\
\mathrm{L}^{-1}\left(\mathrm{c}^{2} \mathrm{u}_{\mathrm{xx}}\right)=\mathrm{L}^{-1}\left\lfloor\mathrm{c}^{2}\left(\sum_{\mathrm{k}=0}^{\infty} \mathrm{u}_{\mathrm{k}}(\mathrm{x}, 0)\right)_{\mathrm{xx}}\right\rfloor=\mathrm{u}_{\mathrm{k}+1}(\mathrm{x}, 0)
\end{gathered}
$$

The zeros component of equation (2) are given in equation (4), and the remaining components $\mathrm{k} \geq 1$ can be determined by using equations (4) and (5). Convergence of the series is given by [8], [9] and [11]

\section{Numerical Examples}

We shall consider the following numerical examples to discuss the accuracy of this class of partial differential equations by ADM.

\subsection{Example}

Using equation (1) with the Cauchy's data $g(x)=\sin x$ and $h(x)=0$. The exact solution is given as

$$
u(x, t)=\sin x \operatorname{cosct}
$$

The series expansion of equation (6) is as follows

$$
\begin{aligned}
\mathrm{u}(\mathrm{x}, \mathrm{t})=\sin \mathrm{x}[1 & -\frac{1}{2}(\mathrm{ct})^{2}+\frac{1}{24}(\mathrm{ct})^{4}-\frac{1}{720}(\mathrm{ct})^{6} \\
& \left.+\frac{1}{2}(\mathrm{ct})^{8}-\frac{1}{3628800}(\mathrm{ct})^{10} \ldots\right]
\end{aligned}
$$

Applying equation (1) to equation (5) of the concept of ADM in this problem, we have that 


\section{International Journal of Science and Research (IJSR)

$\mathrm{u}_{0}=\sin \mathrm{x}$

$\mathrm{u}_{1}=-\frac{1}{2} \mathrm{c}^{2} \mathrm{t}^{2} \sin \mathrm{x}$

$\mathrm{u}_{2}=\frac{1}{24} \mathrm{c}^{4} \mathrm{t}^{4} \sin \mathrm{x}$

$u_{3}=-\frac{1}{720} c^{6} t^{6} \sin x$

$\mathrm{u}_{4}=\frac{1}{40320} \mathrm{c}^{8} \mathrm{t}^{8} \sin \mathrm{x}$

$\mathrm{u}_{5}=-\frac{1}{3628800} \mathrm{c}^{10} \mathrm{t}^{10} \sin \mathrm{x}$

$\mathrm{u}_{6}=\frac{1}{479001600} \mathrm{c}^{12} \mathrm{t}^{12} \sin \mathrm{x}$

$\mathrm{u}_{7}=-\frac{1}{87178291200} \mathrm{c}^{14} \mathrm{t}^{14} \sin \mathrm{x}$

$\mathrm{u}_{8}=\frac{1}{20922789888000} \mathrm{c}^{16} \mathrm{t}^{16} \sin \mathrm{x}$

$\mathrm{u}_{9}=-\frac{1}{6402373705728000} \mathrm{c}^{18} \mathrm{t}^{18} \sin \mathrm{x}$

We can continue in this order to determine as many terms as possible of $\mathrm{u}_{\mathrm{n}} \cdot \mathrm{u}_{0}, \mathrm{u}_{1}, \mathrm{u}_{2}, \mathrm{u}_{3}, \mathrm{u}_{4}, \mathrm{u}_{5}$, are the same as the given series form of equation (6). Taking $c=1$, the correlation between ADM with finite terms of $u_{n}$ and the exact solution is as shown in Figures 1and 2.

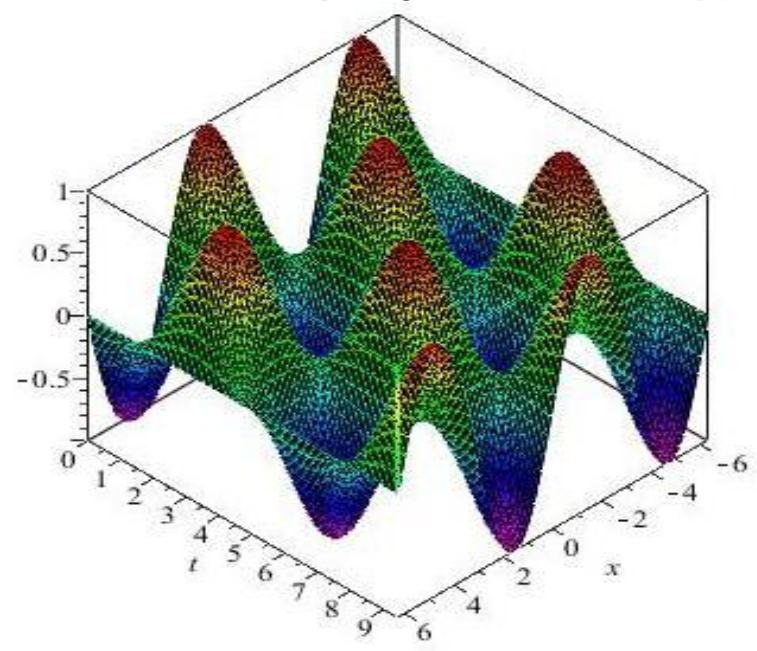

Figure 1: Exact resu1t of Example 3.1

\subsection{Example}

Similarly, using equation (1) with the Cauchy's data $\mathrm{g}(\mathrm{x})$ $=\mathrm{e}^{\mathrm{x}}$ and $\mathrm{h}(\mathrm{x})=\sin \mathrm{x}$. The exact solution is given as

$$
\mathrm{u}(\mathrm{x}, \mathrm{t})=\mathrm{e}^{\mathrm{x}} \cosh \mathrm{t}+\frac{\sin \mathrm{x} \sin \mathrm{ct}}{\mathrm{c}}
$$

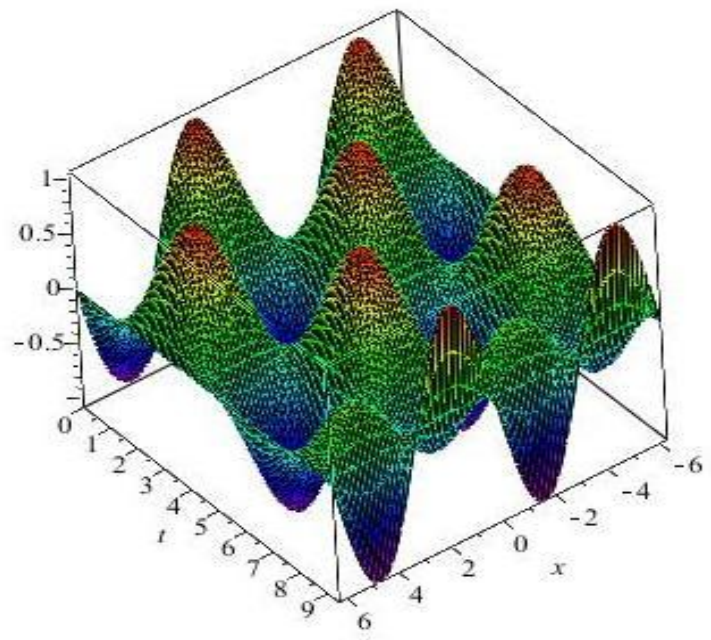

Figure 2: ADM result of Example 3.1

And the series expansion of the exact solution is given as

$$
\begin{aligned}
& u(x, t)=e^{x}\left(1+\frac{c^{2} t^{2}}{2 !}+\frac{c^{4} t^{4}}{4 !}+\frac{c^{6} t^{6}}{6 !}+\ldots\right) \\
& +\frac{\sin x}{c}\left(c t-\frac{c^{3} t^{3}}{3 !}+\frac{c^{5} t^{5}}{5 !}-\frac{c^{7} t^{7}}{7 !}+\ldots\right)
\end{aligned}
$$

Similarly, applying equations (1) through (5) of the concept of ADM, we obtain

$\mathrm{u}_{0}=\mathrm{e}^{\mathrm{x}}+\mathrm{t} \sin \mathrm{x}$

$\mathrm{u}_{1}=-\frac{1}{6} \mathrm{c}^{2} \mathrm{t}^{3} \sin \mathrm{x}+\frac{1}{2} \mathrm{c}^{2} \mathrm{e}^{\mathrm{x}} \mathrm{t}^{2}$

$u_{2}=\frac{1}{120} c^{4} t^{5} \sin x+\frac{1}{24} c^{4} e^{x} t^{4}$

$u_{3}=-\frac{1}{5040} c^{6} t^{7} \sin x+\frac{1}{720} c^{6} e^{x} t^{6}$

$\mathrm{u}_{4}=\frac{1}{362880} \mathrm{c}^{8} \mathrm{t}^{9} \sin \mathrm{x}+\frac{1}{40320} \mathrm{c}^{8} \mathrm{e}^{\mathrm{x}} \mathrm{t}^{8}$

$\mathrm{u}_{5}=-\frac{1}{39916800} \mathrm{c}^{10} \mathrm{t}^{11} \sin \mathrm{x}+\frac{1}{3628800} \mathrm{c}^{10} \mathrm{e}^{\mathrm{x}} \mathrm{t}^{10}$

In this order, we can obtain as many terms as possible of $u_{n}$. And summation of the first few terms of $u_{n}$ gives us what we have in equation (9). The result of the exact solution and that of ADM are shown in figures 3 and 4 with $\mathrm{c}=1$.

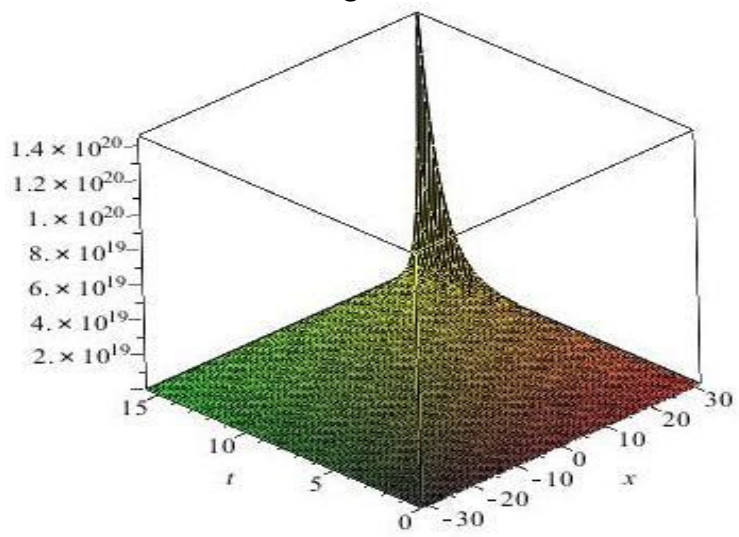

Figure 3: Exact resu1t of Example 3.2 


\section{International Journal of Science and Research (IJSR) \\ ISSN (Online): 2319-7064}

Index Copernicus Value (2013): 6.14 | Impact Factor (2015): 6.391

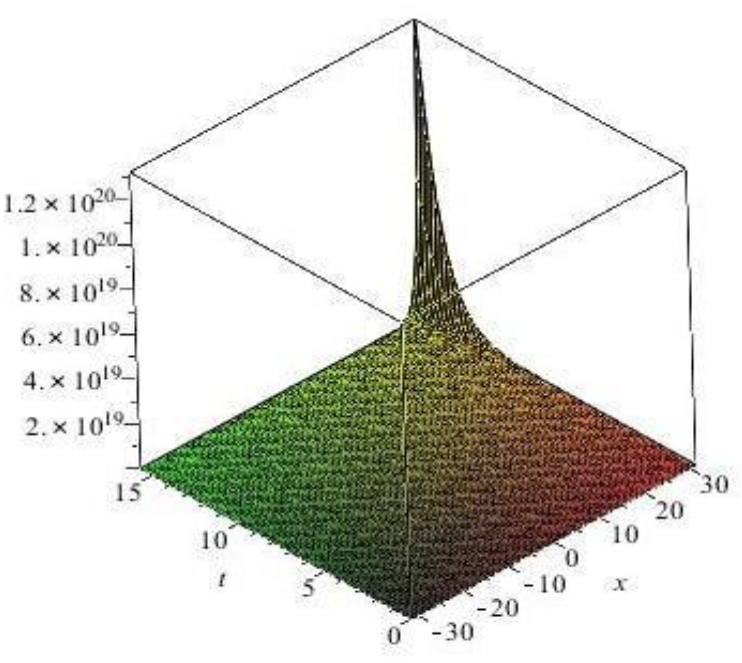

\subsection{Example}

Also, using equation (1) with the Cauchy's data $g(x)=x^{3}$ and $h(x)=\sin x$. The analytical solution is given as

\subsection{Example}

Figure 4: ADM resu1t of Example 3.2

$$
\mathrm{u}(\mathrm{x}, \mathrm{t})=\mathrm{x}^{3}+3 \mathrm{xc}^{2} \mathrm{t}^{2}+\frac{1}{\mathrm{c}}(\sin \mathrm{x} \sin \mathrm{ct})
$$

Also, using equation (1) with the Cauchy's data $g(x)=0$ and $\mathrm{h}(\mathrm{x})=\cos \mathrm{x}$. The analytical solution is given as

$$
u(x, t)=\frac{1}{c}(\cos x \sin c t)
$$

which can be written in series expansion of ct as

$$
\mathrm{u}(\mathrm{x}, \mathrm{t})=\frac{\cos \mathrm{x}}{\mathrm{c}}\left[\mathrm{ct}-\frac{(\mathrm{ct})^{3}}{3 !}+\frac{(\mathrm{ct})^{5}}{5 !}-\mathrm{\aleph}\right]
$$

where

$$
\aleph=\frac{(\mathrm{ct})^{7}}{7 !}-\frac{(\mathrm{ct})^{9}}{9 !}+\frac{(\mathrm{ct})^{11}}{11 !}-\frac{(\mathrm{ct})^{13}}{13 !}+\frac{(\mathrm{ct})^{15}}{13 !}-\ldots
$$

Apply the concept of ADM (equations (1) - (5)), we have $\mathrm{u}_{0}=\mathrm{t} \cos \mathrm{x}$

$u_{1}=-\frac{1}{6} c^{2} t^{3} \cos x$

$\mathrm{u}_{2}=\frac{1}{120} \mathrm{c}^{4} \mathrm{t}^{5} \cos \mathrm{x}$

$u_{3}=-\frac{1}{5040} c^{6} t^{7} \cos x$

$\mathrm{u}_{4}=\frac{1}{362880} \mathrm{c}^{8} \mathrm{t}^{9} \cos \mathrm{x}$

$\mathrm{u}_{5}=-\frac{1}{39916800} \mathrm{c}^{10} \mathrm{t}^{11} \cos \mathrm{x}$

$\mathrm{u}_{6}=\frac{1}{6227020800} \mathrm{c}^{12} \mathrm{t}^{13} \cos \mathrm{x}$

$\mathrm{u}_{7}=\frac{1}{1307674368000} \mathrm{c}^{14^{15}} \cos \mathrm{x}$

We can continue in this order to obtain as many terms as possible of $u_{n} \cdot \sum_{n=0}^{7} u_{n}$ gives the first 8th terms of equation (11). The similarities of the solution using the concept of $\mathrm{ADM}$ and that of the exact solution of equation (11) are shown in Figures 5 and 6 with $c^{2}=1$. In Figure 6 , only finite series of $u(x, t)=\sum_{n=0}^{10} u_{n}$ was considered still the figures are extremely similar.
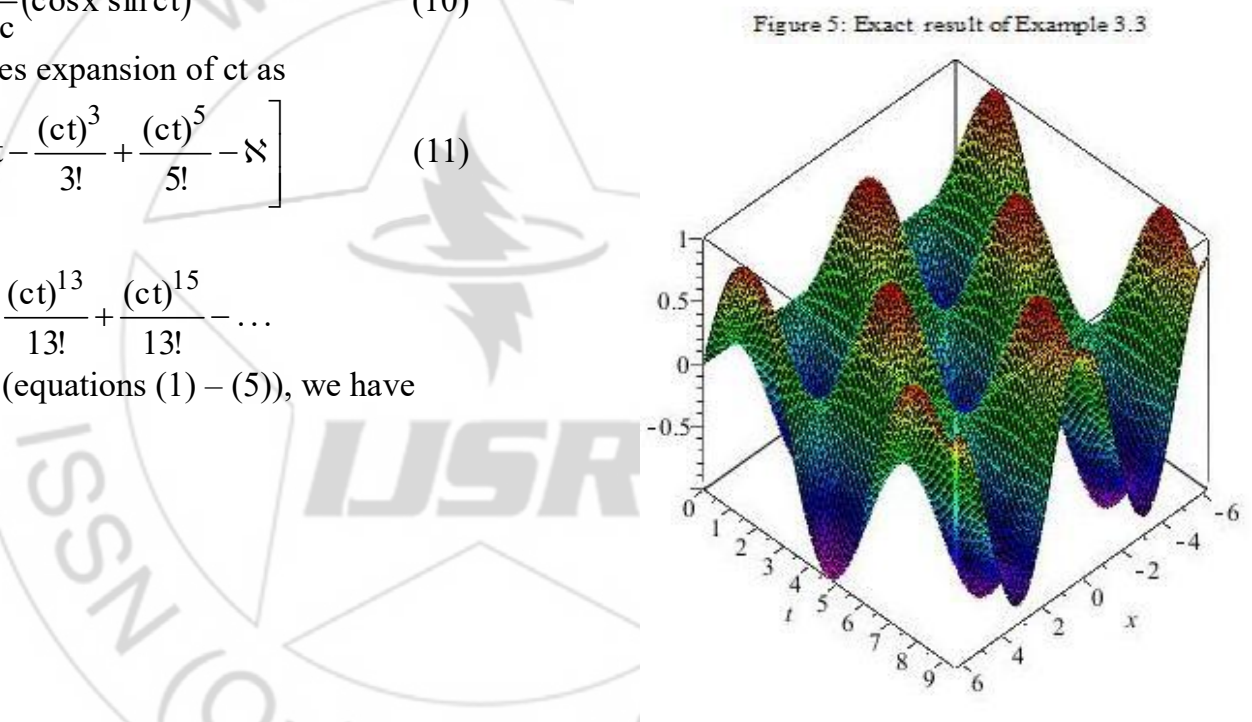

which in series expansion of ct can be given as

$$
u(x, t)=x^{3}+3 x(c t)^{2}+\frac{\sin x}{c} \mathfrak{I}
$$

where

$$
\mathfrak{I}=\mathrm{ct}-\frac{(\mathrm{ct})^{3}}{3 !}+\frac{(\mathrm{ct})^{5}}{5 !}-\frac{(\mathrm{ct})^{7}}{7 !}+\frac{(\mathrm{ct})^{9}}{9 !}-\ldots
$$

Applying the concept of ADM given in equation (1) to (5), we obtain the following

$\mathrm{u}_{0}=\mathrm{x}^{3}+\mathrm{t} \sin \mathrm{x}$

$\mathrm{u}_{1}=-\frac{1}{6} \mathrm{c}^{2} \mathrm{t}^{3} \sin \mathrm{x}+3 \mathrm{c}^{2} \mathrm{xt} \mathrm{t}^{2}$

$\mathrm{u}_{2}=\frac{1}{120} \mathrm{c}^{4} \mathrm{t}^{5} \sin \mathrm{x}$

$u_{3}=-\frac{1}{50400} c^{6} t^{7} \sin x$

$\mathrm{u}_{4}=\frac{1}{362880} \mathrm{c}^{8} \mathrm{t}^{9} \sin \mathrm{x}$

\section{Volume 5 Issue 5, May 2016}




\section{International Journal of Science and Research (IJSR)}

ISSN (Online): 2319-7064

Index Copernicus Value (2013): 6.14 | Impact Factor (2015): 6.391

$\mathrm{u}_{5}=-\frac{1}{39916800} \mathrm{c}^{10} \mathrm{t}^{11} \sin \mathrm{x}$

$\mathrm{u}_{6}=\frac{1}{6227020800} \mathrm{c}^{12} \mathrm{t}^{13} \sin \mathrm{x}$

$\mathrm{u}_{7}=\frac{1}{6227020800} \mathrm{c}^{12} \mathrm{t}^{13} \sin \mathrm{x}$

$\mathrm{u}_{7}=-\frac{1}{1307674368000} \mathrm{c}^{14} \mathrm{t}^{15} \sin \mathrm{x}$

$\sum_{n=0}^{7} u_{n}$ are exactly the same as those in equation (13) which is the exact solution of Example 2.4. In order to give the accuracy of ADM, we compare the result obtained by analytical solution and that obtained by ADM of example 2.4 in figures 7 and 8 taking $\mathrm{c}=1$.
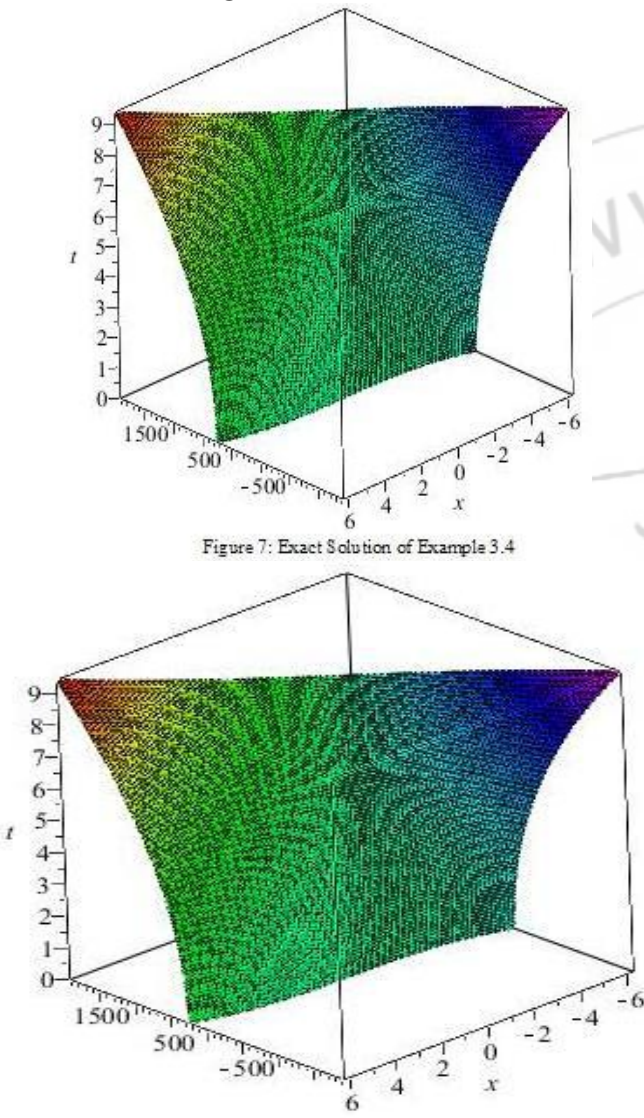

Figure 8: ADM Solution of Example 3.4

\section{Conclusion}

We have successfully given the concept of ADM to One dimensional Wave equation and applied it to solve concrete problems. The decomposition technique developed by G. Adomian [5] in the eighties is of great interest for solving nonlinear functional equations. One can object that it is practically difficult to find the exact sum of an Adomian series. Indeed, we were only able to calculate a finite number of the series' terms. But this is not a great inconvenience because the Adomian series is quickly convergent [8], [9] and [11]. The truncated series, generally involving few terms, is always a good approximation of the solution. The approximation depends explicitly on time and on space variables. This is of great advantage in comparison with classical discretization techniques which only permit calculations to approximate solution for some values of time and space variables. The ADM solution in each case, take into account the parameters and functions contained in the functional equation unlike discretization techniques. Many problems related to this method remain opened for pure applied mathematicians.

\section{References}

[1] E. U. Agom and F. O. Ogunfiditimi, "Adomian decomposition method for Bernoulli differential equations," International Journal of Science and Research, IV(12), pp. 1581-1584, 2015.

[2] F. O. Ogunfiditimi, "Numerical solution of delay differential equations using Adomian decomposition method (ADM)," The International Journal of Engineering and Science, IV(5), pp. 18-23, 2015.

[3] E. U. Agom and A. M. Badmus, "A concrete Adomian decomposition method for quadratic Riccati's differential equations," Pacific Journal of Science and Technology, XVI(2), pp. 57-62, 2015.

[4] M. Almazmumy, F. D. Hendi, H. O. Bokodah and H. Alzumi, "Recent modifications of Adomian decomposition method for initial value problems in ordinary differential equations," American Journal of Computational Mathematics, IV, pp. 228-234, 2012.

[5] G. Adomian, Solving Frontier Problems of Physics: The Decomposition Method. Springer, New York, 1993.

[6] E. U. Agom and F. O. Ogunfiditimi, "Modified Adomian Polynomial for nonlinear functional with integer exponent," International Organization Scientific Research - Journal of Mathematics, XI(6) version 5, pp. 40-45, 2015.

[7] E. U. Agom and F. O. Ogunfiditimi, "Solution of third order time-invariant linear differential equations by Adomian decomposition method," The International Journal of Engineering and Science. 2016; "In Press".

[8] Y. Cherruault, "Decomposition Method: A New Proof of Convergence," Mathematical Computation and Modelling, XVIII(12), pp. 103-106, 1993.

[9] K. Abbaoui and Y. Cherruault, "Convergerce of Adomian Method Applied to Differential Equation," Computational Mathematics and Application, XXVII(5), pp. 103-109, 1994

[10] A. Waleed and C. Luis, "The Adomian Decomposition Method in Turning Point Problems," Journal of Computational and Applied Mathematics, CLXXVII, 187-203, 2005.

[11] K. Abbaoui and Y. Cherruault, "New Ideas for Proving Convergence of Decomposition Method," Computer and Mathematical Applications, XXIX(7) 103 - 108, 1995.

[12] E. U. Agom and F. O. Ogunfiditimi, "Numerical Solution of Fourth Order Linear Differential Equations by Adomian Decomposition Method," British Journal of Mathematics and Computer Science. 2016; "In Press",

[13] P. M. Shearer, "Introduction to Seismology: The wave equation and body waves," San Diego, California, 2010.

[14] L. Knut-Andrea, "The Wave Equation in 1D and 2D, University of Oslo, 2005. 